\title{
Una victoria pírrica en el México posrevolucionario: los finqueros alemanes, las escuelas Artículo 123 y la formación del Estado en la costa de Chiapas, 1934-1942\%
}

\author{
A Pyrrhic Victory in Postrevolutionary Mexico: \\ German Planters, the Article 123 Schools, and State \\ Formation on the Coast of Chiapas, 1934-1942
}

Stephen E. Lewis

California State University, Chico, Estados Unidos

Según el Artículo 123 de la Constitución de 1917, los propietarios mexicanos estaban obligados a pagar la educación de los hijos de sus trabajadores. En 1934, la adopción de la educación socialista por parte de la Secretaría de Educación Pública comprometió a los maestros a promover las reformas agraria y laboral en las fincas cafetaleras chiapanecas. Los finqueros, muchos de origen alemán, lograron ir estorbando las "escuelas Artículo 123", pero se vieron afectados por la reforma agraria en 1939 y por el secuestro de sus fincas durante la Segunda Guerra Mundial. En otras palabras, ganaron su batalla contra la SEP, pero perdieron finalmente la guerra contra el Estado-nación mexicano emergente.

Palabras Clave: Artículo 123; Educación socialista; Soconusco; Chiapas; SEP; Revolución Mexicana; Alemanes.

Article 123 of Mexico's 1917 Constitution stipulated that landowners bore the responsibility of educating the school-aged children of their workers. In 1934, the Ministry of Public Education endorsed socialist education, which required Article 123 teachers to promote agrarian and labor reforms on Chiapas's coffee plantations. The planters, many of whom were of German origin, successfully undermined the Article 123 schools but were targeted first by the Cardenista agrarian reform of 1939 and later by the seizure of their properties during World War II. In other words, they won their battle against the SEP but ultimately lost the war to the emerging Mexican nation-state.

KeYwords: Article 123; Socialist Education; Soconusco; Chiapas; SEP; Mexican Revolution; Germans.

1 Este trabajo forma parte del proyecto de investigación "El indigenismo interamericano: instituciones, redes y proyectos para un continente, 1940-1960" (HAR2008-03099/HIST) financiado por el Ministerio de Ciencia e Innovación de España. Agradecezco a Laura Giraudo y a los dos evaluadores anónimos del AEA sus comentarios. 
A lo largo de los últimos veinte años, las investigaciones históricas sobre la Revolución Mexicana han cambiado de enfoque paulatinamente; ahora menos interesados en la década de la lucha armada (1910-1920), los historiadores están concentrándose cada vez más sobre los dos primeros decenios posrevolucionarios, decenios de reconstrucción, cuando se forjó el moderno Estado-nación mexicano. La más importante institución de ingeniería social durante ese periodo crítico de formación del Estado y de la nación fue la Secretaría de Educación Pública (SEP), fundada en 1921. Además de impartir la enseñanza tradicional, los maestros federales debían de "forjar patria" e introducir las reformas e instituciones federales en regiones inquietas y violentas dominadas muchas veces por caciques, gobernadores, hacendados, finqueros y rancheros poderosos.

Este artículo analiza un programa plenamente radical de la SEP que fue puesto en práctica muy a pesar de la voluntad de propietarios importantes, muchos de ellos extranjeros, en la costa de Chiapas. El conflicto tuvo su origen en la Constitución de 1917. Cuando los constituyentes consideraron medidas para regular las condiciones laborales en el campo, controlar el poder de los grandes finqueros y facilitar el acceso a la educación pública, pensaron satisfacer todas estas demandas con una sola iniciativa legislativa: el Artículo 123 Constitucional. Las autoridades educativas usarían este artículo para obligar a los propietarios a pagar la educación de los niños en edad escolar residentes en sus tierras, pero en el Chiapas rural este experimento estuvo condenado al fracaso casi desde el principio. Coincidió en los años treinta con la radicalización de la SEP y de sus maestros. Los finqueros, que ya se resentían de los mínimos costos asociados con las escuelas, se enfurecieron con los nuevos docentes, quienes también servían de inspectores de trabajo y promotores de la reforma agraria y de la creación de poderosos sindicatos afiliados al gobierno federal. Para 1938, las "escuelas Artículo 123" estaban cediendo ante la resistencia de poderosos finqueros y las contradicciones internas de la SEP, que iba perdiendo su inicial orientación populista.

En Chiapas, la mayoría de las escuelas Artículo 123 se establecieron en las fincas cafetaleras del Soconusco. A finales del siglo XIX, cuando el régimen de Porfirio Díaz fomentó la colonización extranjera a través de la venta de terrenos baldíos y ejidos, los inversionistas de distintas procedencias aprovecharon estas condiciones propicias para establecer fincas dedicadas al cultivo de café. El grupo nacional más numeroso fue el alemán, muchos de cuyos miembros ya habían sido cultivadores de ese producto en 
el vecino país de Guatemala. No sólo tenían experiencia, sino que también se beneficiaron de que los principales bancos de la región fueran alemanes, de que la venta del grano estaba en sus manos y también por que los mercados europeos más importantes se encontraban en Hamburgo. ${ }^{2}$ Durante la etapa más violenta de la Revolución, el primer jefe Venustiano Carranza prohibió que sus tropas saquearan esas fincas en el Soconusco y, según Friedrich Katz, el mismo Carranza solicitó el apoyo del gobierno germano durante la Revolución para protegerse de una posible invasión norteamericana. ${ }^{3}$ Gracias a la política carrancista, en los años veinte los propietarios alemanes estaban en situación ideal para aprovecharse de los altos precios pagados por el café en el mercado mundial. Aunque el grano cotizó poco en los treinta, los impuestos que pagaban los finqueros durante esa década aún constituían entre el 60 y 80 por ciento del ingreso agrícola estatal, y alrededor de un tercio de todos los ingresos del Estado de Chiapas. ${ }^{4}$

Acostumbrados a defender sus intereses y su soberanía frente a los gobiernos estatal y federal, los cafetaleros se enfrentarían también a una ambiciosa SEP y a sus escuelas Artículo 123 en los años treinta. Para el gobierno federal, la educación popular representaba la manera más directa de intervenir en la vida de un proletariado rural parcialmente movilizado y politizado. Las labores de los maestros como inspectores de las condiciones de trabajo, agentes de inmigración y promotores de la organización laboral y el agrarismo estaban destinadas a crear una clientela rural para el emergente Estado-nación federal y, al mismo tiempo, disminuir el poder de las clases finquera y ranchera. Los grandes propietarios se resentían de la intrusión de una institución federal que pretendía averiguar las prácticas laborales y la calidad de vida en sus fincas, y las autoridades estatales se molestaban cuando los docentes federales intervenían en sus dominios, llegando a menudo los maestros Artículo 123 a encontrarse en situaciones precarias y peligrosas. Por una parte, se les había encomendado la implementación de un programa social ambicioso y la conquista de las lealtades de "los de abajo". Por otra, tenían que cobrar sus sueldos raquíticos de propietarios hostiles y armados. Aunque a primera vista parecería que los segundos vencieron tanto a los maestros como a la SEP, veremos que su victoria fue en realidad incompleta frente al poder de un Estado federal cada vez más hegemónico.

2 Spenser, 1988, pp. 65-78; véase también Spenser, 1984, pp. 123-143.

3 Katz, 1981, pp. 511-524.

4 Benjamin, 1995, p. 204. 


\section{Aprendiendo a gatear}

En 1920, después de varios años de violencia, los rancheros y finqueros chiapanecos habían logrado bloquear las reformas que se suelen asociar con la Revolución. Hay cierto grado de confiabilidad en la reflexión de que la Revolución nunca llegó a Chiapas. Según Thomas Benjamin, "la reconstrucción [posrevolucionaria] fue con exactitud eso: la reconstrucción o restauración del orden social porfirista en todo lo posible". ${ }^{5} \mathrm{El}$ "peonaje acasillado", la esclavitud en las monterías, el enganche y las tiendas de raya regresaron a los campos chiapanecos. El Estado de Chiapas no proporcionó los fondos adecuados para la reforma agraria federal; además, esta reforma fue obstaculizada por leyes locales y el programa estaba en manos de los mismos terratenientes. Para 1936 ninguna de las fincas cafetaleras del Soconusco había sido expropiada. Esto se debió, en parte, al débil y corrupto gobierno estatal y a las guardias blancas de los finqueros que aterrorizaban a los que se unían a los agraristas. ${ }^{6}$

Debido a que los gobernadores estatales chiapanecos no podían, o no querían, incomodar a la elite rural, las escuelas Artículo 123 tuvieron una infancia difícil. En otros Estados de la República, como Coahuila y Guanajuato, se fundaron cientos de éstas costeadas por hacendados y rancheros. ${ }^{7}$ En Chiapas, aunque las leyes laborales constitucionalistas habían ordenado la construcción de planteles rudimentarios siempre que hubiese veinte familias residiendo en una propiedad, el sector privado estableció y costeó muy pocas escuelas hasta 1931. Además, éstas apenas cumplían con las metas educativas y sociales de la SEP. Muchas estaban a cargo de maestros que se identificaban con las elites locales y servían de centros de propaganda contrarrevolucionaria. ${ }^{8}$ En 1931 el gobierno federal intentó corregir las fallas de las escuelas Artículo 123 y se tomaron los primeros pasos para que la SEP pudiera ejercer un mayor control. Lo más urgente era impulsar su construcción. En 1932, el director de Educación Federal en Chiapas informó que 252 negocios particulares debían haber establecido una escuela Artículo 123, pero que en realidad sólo existían 55 de éstas. ${ }^{9}$

5 Ibidem, p. 174.

6 Ibidem, pp. 203-204; 213-214.

7 Loyo, 1991, pp. 313-314.

8 Archivo Histórico de la Secretaría de Educación Pública (AHSEP), Secretaría Particular, Año de 1942, 4468 (4595), 1, f. 7. El director general de la Oficina de Escuelas Art. 123, Alberto Terán, al secretario del Ramo, desde México, 7 de noviembre de 1941.

9 AHSEP, Dirección de Educación Federal, Chiapas, 1560 (935), 28, fs. 3-69. En 1933 la SEP en Chiapas reportó 58 escuelas en existencia, faltando 126 por fundar. 
Dos años más tarde, debido a otra serie de reformas a la Constitución y a la Ley Federal del Trabajo, pasaron al control federal y se le otorgó a la SEP la responsabilidad de imponer su construcción a los finqueros de Chiapas, ${ }^{10}$ mientras la Oficina de Estadística Escolar ofreció a los directores e inspector federales incentivos financieros para fundarlas. ${ }^{11}$ Tras la federalización, todo lo relacionado con el curriculum y el personal pasaba a ser competencia de la SEP. Esto cobraba especial relevancia porque la federalización ocurrió un mes después de que el PNR respaldara la educación socialista. La elite rural chiapaneca, que había aprendido a tolerar e ignorar las escuelas pre-federalizadas en sus plantaciones, reaccionaría visceralmente en contra de las nuevas escuelas Artículo 123, ahora federalizadas y socialistas. Consideraban que éstas eran focos de activismo social y político, y tenían razón.

\section{Forjando el Estado central en las escuelas Artículo 123}

La educación socialista en las escuelas Artículo 123 en Chiapas tenía poco que ver con la de las escuelas rurales federales. Las diferencias se explican como consecuencia de las dinámicas del poder local. Típicamente, las segundas se encontraban en comunidades marginales pobladas por mestizos e indígenas dominados por caciques locales y, en ellas, los maestros lanzaban campañas antialcohólicas y de salud pública, patrocinaban los "domingos culturales" y la celebración de fiestas patrias y trabajaban para fomentar un sentido de identidad nacional. ${ }^{12}$

En la zona cafetalera, donde se encontraban la mayor parte de las escuelas Artículo 123, los enemigos del emergente Estado-nación eran muy distintos. Por razones demográficas e históricas, la presencia de la Iglesia era mínima. ${ }^{13}$ Las giras ocasionales de curas ambulantes, con su escasa influencia sobre los trabajadores migrantes y semipermanentes, nunca preocuparon a los forjadores del nuevo México, pero los finqueros y otros miembros de la elite rural chiapaneca representaban una amenaza más seria. Acostumbrados a las exenciones fiscales, a la no observancia de las leyes federales del trabajo y a un gobierno estatal que los favorecía, nunca habían sido sometidos al control federal.

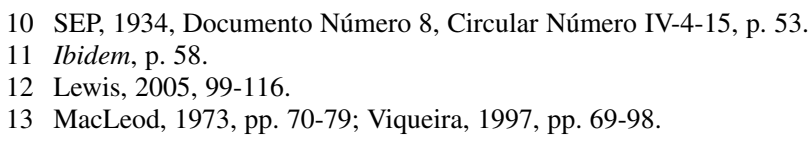


Para los maestros, el reto no podía haber sido más desanimador. La SEP les encargaba sobre todo las dimensiones "libertadoras" de la educación socialista, prestando poca atención a que se cumpliera con la enseñanza tradicional o con su ambicioso proyecto cultural. En 1935, el inspector de la primera zona escolar de Chiapas, Daniel Vassallo, informó que en el "aspecto académico he notado un poquito de deficiencia [...] pero no es de culparse al maestro porque se compensa, y quizá grandemente, con la intensa labor social que se viene desarrollando". ${ }^{14}$ Un mes más tarde, Vassallo anotaría que "tropezamos con dificultades que nos presenta un pequeño sector de personas a la antigua, que quisieran que sus hijos asistiesen a la escuela sólo para aprender a leer, escribir y contar". ${ }^{15}$ Tampoco interactuaban mucho con los migrantes indígenas que llegaban a las fincas cada otoño para la "pizca" o "tapisca" (recolección del café); la movilización, politización, y organización laboral del proletariado mestizo fueron más importantes en la zona cafetalera.

Las labores más conflictivas de los maestros eran la organización de los trabajadores en sindicatos afiliados a la Confederación de Trabajadores Mexicanos (CTM) y el fomento de la reforma agraria. Como relató el mismo Vassallo, la campaña sindicalista implicó un fuerte enfrentamiento con los intereses más poderosos del Estado:

El criterio del señor Gobernador del Estado, que así me lo ha indicado, es que los maestros no deben atender estas actividades ya que él tiene empleados para ello, pero resulta que alguno de estos empleados organiza su sindicato poniéndose previamente de acuerdo con el patrón y entonces resulta un sindicato blanco integrado por las personas más allegadas al patrón. ${ }^{16}$

Vassallo y sus maestros pretendían regular las prácticas laborales, los sueldos, las relaciones de poder y la calidad de vida en las fincas. El maestro Amadeo Tercero, por ejemplo, tomaba medidas para que se respetaran las garantías de la Ley Federal del Trabajo, y en la finca "El Retiro", donde trabajaba, vigilaba "que las tareas no [fueran] excesivas, que el tiempo de

14 AHSEP, Departamento de Escuelas Rurales (DER), 1332 (191), 4, f. 13. Informe bimestral del inspector de la 1. ${ }^{\mathrm{a}}$ zona de Chiapas, Daniel Vassallo L., al jefe del Departamento de Escuelas Rurales, desde Huixtla, Chis., 8 de agosto de 1935.

15 Ibidem, fs. 16-17. Informe de Daniel Vassallo L. al secretario de Educación Pública, DER, desde Huixtla, Chis., 2 de septiembre de 1935.

16 Ibidem, f. 14. Informe Bimestral de Daniel Vassallo L. al jefe del DER, Sección de Escuelas Rurales, desde Huixtla, Chis., 8 de agosto de 1935. 
trabajo no [fuera] mayor de las ocho horas diarias, y que no se trat[ara] mal a los trabajadores a quienes la mayoría de maestros esta[ban] procurando organizar en Sindicatos para su defensa". ${ }^{17}$ Tercero también tenía responsabilidades como agente de inmigración en esta temprana fase de la formación del Estado mexicano. En 1937 el mismo maestro escribió:

Como maestros socialistas revolucionarios, nos hemos impuesto la obligación de vigilar que en los centros de trabajo de esta región cafetera que está en manos de alemanes en su mayoría, no entren clandestinamente braceros guatemaltecos a sustituir a los mexicanos, por ser peligrosos por las razones siguientes: que desconocen nuestras Leyes de Trabajo, siendo ésto motivo a que se conformen a ganar un salario bajo, aceptan tareas excesivas, más de las ocho horas de trabajo diario, y aguantan cuando el finquero les da un mal trato [...] siendo ésta la causa por la que en la mayoría de las veces les niegan trabajo a los mexicanos y prefieren a los guatemaltecos. ${ }^{18}$

Tercero promovió la organización laboral de una manera activa y directa, intentando formar ese mismo año un Sindicato de Trabajadores del Campo en "El Retiro". Según su relato, el administrador alemán de la finca — "miembro de una organización hitleriana"- amenazó con despedir los trabajadores en proceso de organizarse; más tarde, intentó obstaculizar el proceso de registro oficial ofreciendo mordidas al agente municipal y al mismo Tercero. El administrador envió otro empleado (alemán) a Tapachula para ofrecer más sobornos y convencer a las autoridades de que saboteasen el Sindicato; posteriormente se desplazó personalmente con el mismo fin. Una vez regresado a "El Retiro", el administrador afirmó que "para lograr la disolución del grupo está dispuesto a tirar los miles de pesos que sean necesarios, porque no tolerará la organización de un Sindicato en la finca". ${ }^{19}$ Finalmente, el maestro ganó esta batalla, por lo menos a corto plazo. Tras el reconocimiento del Sindicato, los trabajadores de "El Retiro" pudieron negociar con los dueños un contrato colectivo de trabajo.

El papel de los "maestros Artículo 123" en la reforma agraria era igualmente provocador. Después de la reforma al Código Agrario en marzo de 1934, la misma que extendió el derecho a solicitar el reparto de tie-

17 AHSEP, Dirección General de Enseñanza Primaria en los Estados y Territorios (DGEPET), Estado de Chiapas, 6130 (80), 3, f. 9. El maestro Art. 123 Amadeo Tercero al director general de enseñanza primaria y rural en los Estados y Territorios, desde la Finca "El Retiro", Chis., 13 de septiembre de 1937.

18 Idem.

19 AHSEP, DGEPET, Estado de Chiapas, 6130 (80), 3, f. 11. Amadeo Tercero al director general de enseñanza primaria y rural, desde la Finca "El Retiro", Chis., 24 del septiembre de 1937. 
rras a los "peones acasillados", los maestros de la zona cafetalera se dedicaron a facilitar los trámites en sus comunidades. A finales del mismo año, esos peones y trabajadores ya habían solicitado el reparto de tierras en los lugares donde había escuelas Artículo 123. Cuando la burocracia correspondiente no cumplía con las demandas de los agraristas, la SEP esperaba que los maestros dirigieran invasiones de tierras. En 1935 los docentes encabezarían cincuenta de estas invasiones para poner a las autoridades frente a una situación de facto. ${ }^{20}$

En su papel de activistas sociales, los maestros de las escuelas Artículo 123 dejaron un legado impresionante a pesar de la fuerza de los finqueros y de la falta de apoyo por parte del Gobierno estatal. En 1935 consiguieron cerrar las anticonstitucionales tiendas de raya en 34 fincas y fundar, en su lugar, cooperativas de consumo. Varios maestros organizaron huelgas para protestar por las violaciones a la Ley Federal del Trabajo. ${ }^{21}$ Otros (casi todos eran hombres) organizaban ligas femeninas y fomentaban la formación de una conciencia proletaria. Promovían también campañas antialcohólicas, en las que se cuestionaban las cantinas de los finqueros, y dirigían campañas de salud que obligaban a mejorar la infraestructura de las fincas. En el sur del Estado, los maestros del circuito Artículo 123 lanzaron una campaña para promover el uso de la moneda nacional vigente, ya que todavía circulaban monedas guatemaltecas y billetes que habían sido impresos por los caciques revolucionarios durante las grandes revueltas de 1914 a $1920 .^{22}$

Mientras que los maestros desarrollaron activamente las campañas sindicalista, agrarista y de salud pública en las escuelas Artículo 123, perdieron relevancia otras responsabilidades sociales, como la educación sexual y las actividades desfanatizadoras y nacionalistas. La necesidad de establecer la presencia federal en Chiapas era demasiado urgente. El agrarismo y el sindicalismo federal consiguieron importantes resultados: ambos permitieron pacificar una población rural inquieta mientras creaban una clientela leal para el gobierno federal. Los agraristas se veían incorporados a la Confederación Campesina Mexicana (CCM) y la Confederación

20 AHSEP, DER, Delegación Chiapas, 1375 (236), 10, f. 68.

21 Ibidem, 1375 (236), 26, fs. 16-18. El director de educación federal Elpidio López al secretario de Educación Pública, DER, desde Tuxtla Gutiérrez, Chis., 14 de agosto de 1935.

22 Ibidem, 1332 (191), 3, f. 16, f. 2. "Informe de labores del 3er. Bimestre, en la parte relativa a las Escuelas rurales y Artículo 123", de P. Arturo Mota, inspector federal 2da. zona, al profesor Elpidio López, director de Educación Federal en Tuxtla Gutiérrez, 5 de agosto de 1935. 
Nacional Campesina (CNC), mientras que el proletariado rural se unía a la CTM y a la Confederación Regional Obrera Mexicana (CROM). En marzo de 1938, el congreso constitucional del Partido de la Revolución Mexicana (PRM) consolidó los bloques campesino y trabajador dentro de la estructura corporativista del nuevo Estado mexicano.

\section{Los finqueros contraatacan}

La contraofensiva de los propietarios tenía un aspecto legal y litigioso y otro amenazador y violento. El programa de las escuelas Artículo 123 se apoyó en una sola frase de la reformada Ley Federal del Trabajo, que decretaba que los propietarios debían establecerlas siempre que el número de hijos de trabajadores residentes en un centro industrial o rural excediese un total de veinte y la distancia a la escuela rural federal más cercana fuese mayor de tres kilómetros. ${ }^{23}$ Los patrones y sus abogados analizaron cuidadosamente esta frase con el objeto de lograr su exención. Los términos "hijos de trabajadores", "centro rural" y "comunidad", por ejemplo, debían definirse con precisión para conseguir que los dueños de las fincas cumplieran con sus obligaciones. Sin embargo, cada entidad estatal y federal tenía su propia interpretación de esta ley y la SEP se encontró paralizada por la confusión, siendo incapaz de presentar un frente único contra las maniobras de los finqueros. ${ }^{24}$ Cuanto más poderoso era el patrón, tenía más capacidad para exponer estas debilidades y usar su influencia con el fin de recibir un trato favorable. Años después, Alberto Terán, director general de enseñanza en los Estados y Territorios, notaría que "muchas empresas poderosas están eludiendo el cumplimiento de la Ley cuando gran número de pequeñas fincas agrícolas tienen sus respectivas escuelas Artículo 123", ${ }^{25}$

$\mathrm{Su}$ buen funcionamiento también se vio obstaculizado por autoridades locales que se identificaban con los finqueros. El inspector de la segunda zona escolar, P. Arturo Mota, explicaba que las multas de la SEP no tenían

23 "Artículo 111. Son obligaciones de los patrones: Fracción VIII. Establecer y sostener escuelas elementales en beneficio de los hijos de los trabajadores, cuando se trate de centros rurales situados a más de tres kilómetros de las poblaciones, y siempre que el número de niños en edad escolar sea mayor de veinte", en SEP, 1934, p. 52.

24 AHSEP, Secretaría Particular, 4468 (4595), 1, f. 5, 8. El profesor Alberto Terán, director general de enseñanza, Oficinas de escuelas Art. 123, al secretario del Ramo, desde México, D.F., 7 de noviembre de 1941. Véase también Loyo, 1991, pp. 321-324.

25 Ibidem, f. 16. Loyo, 1991, pp. 321-23. 
el efecto esperado: su imposición no solía reflejarse en el pago puntual de los maestros, pues en ocasiones los directores de las oficinas locales de Hacienda eran amigos o parientes de los hacendados recalcitrantes..$^{26}$ En 1938 se prohibió en Tapachula la participación de los maestros en la política local y se les negó el derecho a sindicalizar a los obreros. Esta medida pretendía anular la agenda socialista de las escuelas, mientras que los directores federales de la SEP impulsaban una escuela moderna vinculada al Sindicato, las comunidades agrarias y las cooperativas. Cuando las fuerzas locales se unieron en contra del proyecto educativo nacional, la SEP y el gobierno federal aparentaban ser todo menos un Leviatán.

El caso de la dinastía Braun puede ilustrar la tenacidad de los finqueros poderosos. Hijos de ciudadanos norteamericanos de origen alemán, Enrique y Fernando Braun nacieron en Sonora durante el temprano Porfiriato. Cuando llegaron a Tapachula, unos veinte años después, comerciaban con pan, luego pieles y finalmente, café. Enrique se vinculó por casamiento con una familia terrateniente, mientras que Fernando alcanzó el cargo de jefe político. Como porfirista y luego como huertista, el segundo ganó notoriedad tras su salvaje exterminio de simpatizantes maderistas en el Soconusco. Utilizando una hábil combinación de capital financiero y poder político, ambos hermanos acumularon gran cantidad de propiedades durante el Porfiriato tardío y los años revolucionarios. ${ }^{27}$

En los años treinta, Enrique Braun era el finquero más poderoso de Chiapas. Sus tierras cubrían la mayor parte de los municipios de Unión Juárez y Cacahoatán en el Soconusco, y sostenía a siete maestros y a cinco escuelas en cinco de sus fincas, donde llegó a contar con más de mil trabajadores. Su oposición a las escuelas no se debía tanto al costo que éstas representaban, que era mínimo, como a la intrusión de los maestros y oficiales radicales de la SEP en su dominio. Según los peones acasillados de sus fincas "El Achotal" y "San Rafael", quería demostrar "que para él no había leyes, ni nadie que lo obligara a cumplirlas". ${ }^{28}$ Luchaba constantemente para que fueran destituidos los maestros de sus escuelas; cuando venían los inspectores de la SEP, escondía a los niños para que no apare-

26 AHSEP, Delegación Chiapas, DER, 236, 13, f. 22. El subsecretario de Enseñanza Rural Escuelas Artículo 123, Gabriel Lucio, al secretario de Hacienda y Crédito Público, México, D.F.

27 García de León, 1985, pp. 38, 68, y 169; Ortiz y Toraya, 1985, p. 109.

28 AHSEP, DGEPET, Estado de Chiapas, 6131 (79), 13, f. 30. El secretario general de Educación Daniel Ruiz al secretario general de Educación Federal en Tuxtla Gutiérrez, desde Jitotol, Chis., 5 de agosto de 1938. 
cieran en los padrones oficiales, presentaba registros falsificados, amenazaba y frecuentemente no pagaba a sus maestros. ${ }^{29}$

El obstruccionismo de Braun seguía pautas predecibles. Primero, negaba que existiera una propiedad determinada, o alegaba que era parte de una finca más grande donde una escuela ya había sido establecida. Posteriormente, argumentaba que existía otro centro escolar a menos de tres kilómetros de la propiedad en cuestión. Después cuestionaba la veracidad del padrón escolar de la SEP o pedía un nuevo padrón después de la pizca, cuando había menos de veinte niños en sus fincas. ${ }^{30}$ Por último, recurría al amparo del sistema judicial.

Desgraciadamente para Braun, el inspector de su zona escolar era nada menos que el enérgico Daniel Vassallo, el cual luchaba para que los finqueros cumplieran con sus obligaciones constitucionales, y sentía un gran desprecio por Braun y los demás ricos terratenientes de herencia alemana. Vassallo estableció 73 escuelas Artículo 123 en los primeros 18 meses siguientes a la federalización y 146 más durante toda la campaña. Ganó un premio por fundar el mayor número de escuelas a nivel nacional. ${ }^{31}$ Es evidente que Vassallo también se ganó el odio de los finqueros como Braun, que intentaron persuadirle, por medio de dinero y amenazas de muerte, para que no los obligara a respetar la ley.

Una batalla típica entre Braun y Vassallo se peleó en la finca "Santo Domingo". En agosto de 1934 se reportó que sólo 26 niños asistían a clases, impartidas por un maestro y una asistente. De acuerdo con los reglamentos de la SEP, por lo menos cincuenta estudiantes tenían que asistir regularmente para justificar dos instructores. Según el maestro, los caporales de la finca habían obligado a todas las mujeres residentes a reportarse ese día para la tapisca, sabiendo que tenían que ocuparse de la comida y de sus otros hijos, y que mandarían en su lugar a los niños en edad escolar. ${ }^{32}$ Una vez que la mayoría de los niños estuvieron en la tapisca, Braun envió a su tenedor de libros a la escuela para pasar lista. Cuando el inspector

29 Ibidem, 14, fs. 6, 7 y 26.

30 Su hábil manejo de los flujos temporales de trabajadores provocó que Rafael Ramírez, director de Educación Rural, dictara un circular prohibiendo la realización de más de un padrón por año. Véase AHSEP, DER, 2384 (148), 1, fs. 45-49. Circular No. IV-27-128, del jefe del DER Rafael Ramírez a los directores de Educación Federal, inspectores generales e inspectores instructores, desde México, D.F., 10 de julio de 1934.

31 Pérez Palacios, 1987, p. 82.

32 AHSEP, DGEPET, 6131 (79), 14, f. 6. El director de la Escuela Artículo 123 Juan D. Noriego al inspector Daniel Vassallo L., desde Santo Domingo, 17 de agosto de 1934. 
Vassallo denunció la maniobra, Braun pidió que la SEP autorizase un nuevo padrón escolar para verificar el número de niños residentes en sus fincas. La SEP le negó la solicitud. Braun argumentó entonces que los padrones escolares originales eran ilegales dado que él no los había firmado. ${ }^{33}$ Cuando las autoridades de la SEP en Chiapas le recordaron que uno de sus empleados lo había firmado (y legalizado), Braun presentó su propio padrón, que fue ignorado por la SEP.

Finalmente, Braun se dio cuenta de que ni el inspector Vassallo ni el director federal de Educación Septimio Pérez Palacios iban a permitirle estorbar a sus escuelas y habló con altas autoridades de la SEP en el Distrito Federal. Al regresar a sus fincas se jactó con Vassallo de que "estuvo tomando copas con el señor Ministro" y que todo había sido resuelto a su favor. Pero su victoria fue solamente parcial y temporal. Una vez que Vassallo y las autoridades estatales de la SEP reconfirmaron la necesidad de mantener dos instructores en "Santo Domingo", el asistente fue nuevamente nombrado. ${ }^{34}$

En repetidas ocasiones Braun escribió a la SEP pidiendo otro inspector de zona, dado que Vassallo "no es competente ya que su ilustración es sumamente deficiente como lo demuestra en sus escritos tan faltos de ortografía". ${ }^{35}$ En su contraataque Vassallo afirmó que para Braun el único inspector bueno era un inspector débil. De hecho, Vassallo fundó tantas escuelas que en 1935 la SEP tuvo que dividir su zona escolar en tres. Inspectores extraordinarios como Vassallo cabían dentro de la SEP "socialista" a mediados de los años treinta, pero se encontrarían bloqueados por la misma SEP a finales de esa década.

Si los finqueros se oponían a las escuelas Artículo 123 con tanta firmeza, y si los gobiernos estatal y federal les negaban el apoyo concreto y constante que necesitaban, ¿había alguien que realmente las apoyara? La literatura posrevisionista de la historia de la educación sugiere que muchas comunidades rurales se apropiaban selectivamente de aquellos elementos del programa educativo oficial que les convenían, de acuerdo con sus realidades. ${ }^{36}$ Los propios estudiantes y padres de familia eran los que más apo-

33 Ibidem, 14, f. 7. El director federal de Educación Septimio Pérez Palacios al señor Enrique Braun, Tapachula, Chis., desde Tuxtla Gutiérrez, Chis., 24 de agosto de 1934.

34 Ibidem, 14, fs. 9 y 21.

35 Ibidem, 13, f. 11. Enrique Braun al director de Educación Pública, Tuxtla Gutiérrez, 17 de junio de 1938.

36 Rockwell, 1994, pp. 170-208; Vaughan, 1997; varios capítulos en Quintanilla y Vaughan (coords.), 1997. 
yaban a Amadeo Tercero, puesto que ya habían asimilado la idea de que la asistencia a la escuela los haría exitosos. ${ }^{37}$ En una carta dirigida al presidente Lázaro Cárdenas, el Sindicato de Trabajadores del Campo de la Finca "El Retiro" defendía así a su maestro:

protestamos atenta pero enérgicamente contra las maniobras antirrevolucionarias de la reacción capitalista extranjera representada en su mayoría por el Sindicato de Cafeteros del Soconusco [....] Todas estas mentiras sucias y descaradas, las refutamos. La orientación que estamos recibiendo de los profesores federales, la consideramos de un valor inapreciable, por ser de verdadera ideología clasista basada en el socialismo científico con apoyo en el materialismo histórico. ${ }^{38}$

Cientos de chiapanecos escribían a la SEP pidiendo la fundación de una escuela en su finca o que se les mandara un maestro. La mayoría de los padres se solidarizaban con los docentes, pues compartían una vida precaria y de escasez en las plantaciones calurosas del Soconusco. Sobre el membrete de su Sindicato los padres argumentaban que la educación gratis y laica era una de las grandes conquistas de la Revolución. Los chiapanecos en el Soconusco siguieron apoyando a las escuelas Artículo 123 en los años cuarenta, aún cuando la educación socialista ya había pasado a la historia. A principios de los años treinta, la SEP había luchado contra la indiferencia de las poblaciones rurales en el Soconusco. Apenas diez años después, la misma SEP no podía satisfacer la demanda popular de sus escuelas. ${ }^{39}$

\section{El eclipse del poder alemán en la zona cafetalera}

Hasta la primavera de 1939, los finqueros y rancheros de Chiapas se opusieron firmemente a las intervenciones e innovaciones del Gobierno central de México. Utilizando medios más o menos violentos, habían desbaratado y boicoteado el sistema impositivo porfiriano, las leyes laborales carrancistas, la Ley Federal del Trabajo en 1931 y las escuelas Artículo

37 Según Harvey Graff, la idea que la escolarización conduce al éxito puede surtir efecto incluso cuando la evidencia empírica sugiere que la educación pública no necesariamente mejora las oportunidades futuras del estudiante. Véase Graff, 1979.

38 AHSEP, DGEPET, Chiapas, 6130 (80), 3, f. 26. El secretario general del Sindicato de Trabajadores del Campo de la Finca "El Retiro", Octavio García, al presidente Lázaro Cárdenas, desde la Finca "El Retiro," Chis., 12 de julio de 1938.

39 Lewis, 2005, pp. 173-80; 194-201. 
123. Asimismo habían sido capaces de controlar el ritmo de la reforma agraria. Nunca se habían redistribuido tierras de propiedad privada que ya estaban en explotación. Tal era la influencia de los rancheros y finqueros del Estado, que Cárdenas no se atrevió a repartir tierras en el Soconusco hasta finales de su sexenio, momento en el que la reforma agraria se estaba moderando en otras zonas del país. Promover con anterioridad una reforma mayor habría sido invitar a una confrontación abierta en un momento en el que el gobierno federal se encontraba aún en una posición débil frente al sector privado.

La reforma agraria cardenista en Chiapas coincidió con cambios nacionales e internacionales que repentinamente volvieron a los finqueros de origen alemán más vulnerables de lo previsible. Al principio del sexenio cardenista amplios sectores de la población mexicana simpatizaban con el fascismo europeo, encontrándose entre ellos numerosos comerciantes de origen alemán, italiano y español afincados en Chiapas. El Club Alemán de Tapachula, que exhibía una bandera nazi y un enorme retrato de Hitler, organizaba lucidas y llamativas fiestas cada 20 de abril para conmemorar el cumpleaños del Führer. Se celebraban abiertamente y recibían cobertura de la prensa local. ${ }^{40}$ En otros lugares de México, distintos grupos de derechas como los nacionalistas, los antisemitas, los anticomunistas Camisas Doradas, los sinarquistas y la Falange española, cobraron tanta fuerza que Cárdenas se sintió obligado a desplazar la oposición entre conservadores y liberales mexicanos al campo de batalla de la Guerra Civil Española. ${ }^{41}$ En marzo de 1937, México era el único país occidental que apoyaba militarmente a la República Española contra el general Franco y su coalición de fascistas y católicos conservadores.

La conspiración en contra de los finqueros de origen alemán se llevó a cabo por la administración cardenista y sus aliados de izquierda en los sectores laboral y educativo. Tratando de conformar un "frente popular" de apoyo a la República Española, la administración se vio reforzada por las condiciones locales. El lamentable estado de la industria cafetalera chiapaneca obligó a numerosos propietarios a endeudarse con prestamistas alemanes. En mayo de 1938 la colonia chiapaneca del Distrito Federal advirtió que el Soconusco era controlado "por latifundistas y capitalistas alemanes y españoles, por nazis y la Falange Española, mediante la propie-

40 Montiel, 1979, p. 110; “Aniversario del Natalicio del Fuehrer Hitler”, El Sur de México, Tapachula, Chiapas, 21 de Abril de 1938, XIV-717, p.1.

41 Schuler, 1998, pp. 55-59. 
dad de la tierra o sus préstamos usureros". ${ }^{42}$ Se inició entonces también la leyenda negra sobre las prácticas laborales alemanas de explotación de los indígenas con el peonaje por deudas. Esta acusación ha perdurado en la historiografía a pesar de que dichas prácticas coercitivas se habían retomado de los propietarios guatemaltecos y mexicanos y no existen evidencias de que los alemanes tratasen a sus trabajadores peor que los rancheros, latifundistas y enganchadores mexicanos. ${ }^{43}$

En cualquier caso, el nacionalismo, la envidia y las acusaciones de prácticas excluyentes e injustas en la actividad que desarrollaban los alemanes, condujeron a que varios políticos chiapanecos pidiesen la reclusión de éstos, incluso antes de que México declarase la guerra a Alemania. ${ }^{44}$

En enero de 1939 Alborada, la publicación oficial de la CTM en Chiapas, incitó a los maestros rurales y Artículo 123 a que promoviesen la agitación para preparar una expropiación masiva. ${ }^{45}$ La reforma agraria acabó por llegar al Soconusco en marzo, dos semanas antes de que Madrid cayese ante Franco y sus aliados fascistas. Este sería el punto más dramático de la de por sí oscura historia del agrarismo en Chiapas. El gobernador Efraín Gutiérrez, amigo de Cárdenas, eligió como principal blanco a un mexicano reaccionario descendiente de alemanes, el ya mencionado Enrique Braun. Los cardenistas, acertadamente, identificaban a este personaje con la facción callista del Estado y con el asesinato de varios huelguistas y líderes sindicales de su plantación. Además, Braun dio al gobernador la oportunidad de obtener una lucrativa mordida: según relata Antonio García de León, la inmunidad frente a la expropiación tenía un precio de 300.000 pesos para Gutiérrez. Braun no podía permitirse desembolsar esa cantidad a causa del desplome de los precios del café y, resentido por su impotencia para regir los devenires de Tuxtla, contestó, al parecer, "[1]e doy trescientas mil chingadas y que las tierras sean para los indios". ${ }^{46}$

Casi la mitad de las 7.988 hectáreas expropiadas en marzo de 1939 era propiedad de Braun. En las tierras que habían pertenecido a "Eureka", "Santo Domingo", "Alpujarras", "La Central", "Tonintaná", "Buenavista", "Highlands", "Santa Teresa Guarumo”, "San Rafael”, "Cerro del Carmen”,

42 Colonia Chiapaneca. Revista Anual de sus Actividades, México, 21 de mayo de 1938.

43 Sobre Guatemala, véase McCreery, 1994, p. 233; sobre Chiapas, véase Baumann, 1983.

44 "Alemanes y Japoneses en Chiapas serán concentrados a Perote, Ver.", El Sur de México, Tapachula, 11 de mayo de 1942, XVII-922, p. 1.

45 "Conflictos obrero-patronales en la zona platanera", Alborada, Organo de la Federación de Trabajadores del Estado de Chiapas (CTM), Tuxtla Gutiérrez, 18 de enero de 1939, II-53, p. 15. 46 García de León, 1985, p. 213. 
"La Trinidad" y "El Desengaño" se crearon seis ejidos. ${ }^{47}$ Tal como establecía la ley, Braun conservó al menos 300 hectáreas de cada una de sus propiedades. Pero se quejó amargamente ante Cárdenas en un telegrama de que todas sus propiedades, fruto de 40 años de duro trabajo, habían sido afectadas, mientras la mayoría de las plantaciones del Soconusco permanecían intactas. ${ }^{48}$ Lo excepcional de la expropiación de marzo de 1939 no fue la modesta extensión expropiada, sino que las plantaciones de Braun figuraban entre las más productivas de México. Otro aspecto polémico fue que la mayoría de los beneficiados fueron guatemaltecos recién naturalizados en México. ${ }^{49}$ Por último, hay que destacar el significado simbólico del reparto. Sugería el amanecer de una nueva era en la que los poderosos rancheros, propietarios y políticos chiapanecos tendrían que someterse, por lo menos ocasionalmente, al control federal.

Poco después de que las expropiaciones de 1939 y 1940 confirmasen la nueva fortaleza del gobierno central en Chiapas, sucesos internacionales darían otro serio golpe a los propietarios de ascendencia alemana. La Segunda Guerra Mundial los convirtió, de la noche a la mañana, en parias. Más aún, una alianza entre los gobiernos mexicano y estadounidense, muy improbable en otras circunstancias, situó a las plantaciones alemanas al servicio del esfuerzo bélico de los Estados Unidos y ocasionó la reclusión de sus propietarios en el campo de Perote, Veracruz.

México entró oficialmente en guerra el 25 de mayo de 1942 después de que submarinos alemanes hubiesen torpedeado dos petroleros en el Golfo de México. En junio se estableció por decreto presidencial la "Junta intersecretarial relativa a propiedades y negocios del enemigo" cuyo cometido era determinar qué negocios alemanes y japoneses quedarían temporalmente en manos del gobierno. Esta Junta, cuyos funcionarios eran enemigos declarados del agrarismo como Luis Cabrera, se encargaba de dirigir dichos negocios..$^{50}$ La confiscación se mantuvo hasta 1946 y un $80 \%$ de los afectados eran alemanes. Sesenta y siete de las 75 plantaciones de café que en Chiapas estaban en manos alemanas fueron confiscadas en 1942, junto

47 "Fernando Braun también perdió tierras. Cómo fue hecha la repartición de tierras en el Soconusco", Chiapas Nuevo. Periódico de acción política, social e informativa. Organo del Comité Regional del P.R.M., Tuxtla Gutiérrez, 23 de marzo de 1939, II-112, p. 4.

48 Archivo General de la Nación (AGN), Ramo Presidentes, Cárdenas, 404.1/3390. Enrique Braun al presidente Lázaro Cárdenas, en Tapachula, 22 de septiembre de 1939.

49 "El pleno reparto de tierras", El Sur de México, Tapachula, 3 de marzo de 1939, XIV-761, p. 1; García de León, 1985, p. 276.

50 Von Metz, 1988, pp. 214-216. 
con dos plantaciones de banano y un puñado de comercios y comercializadoras situados en Tapachula y Tuxtla. ${ }^{51}$ La mayoría de los grandes nombres del café en Chiapas fueron afectados por la reclusión en Perote: los Kahle, los Giesemann, los Pholenz y los Hammer fueron desplazados sin ninguna ceremonia. ${ }^{52}$

¿Cuál fue el destino de las escuelas Artículo 123 en las plantaciones durante el periodo de gestión gubernamental? En los cuatro años en que el gobierno federal dirigió las plantaciones mediante el Fideicomiso de Cafeteros de Tapachula, la SEP habría podido dar un nuevo impulso al decaído programa de estas escuelas. Sin embargo, por el contrario, entró en una etapa de inactividad e irresponsabilidad sin precedentes, durante la cual las escuelas existentes fueron desapareciendo mientras el fideicomiso, división del Banco Nacional de Comercio Exterior, arruinaba las plantaciones. Benjamín apunta que "los funcionarios del fideicomiso no eran hombres de negocios eficientes ni reformadores sociales". Existía una corrupción rampante y, "a pesar del alza en los precios del café durante la guerra, la producción en las fincas embargadas decayó a menos de la mitad durante el tiempo que duró el embargo".53 Los administradores del fideicomiso violaban regularmente la Ley Federal del Trabajo ya que suprimían las huelgas y contrataban trabajadores guatemaltecos por salarios inferiores al mínimo legal; parece que la diferencia entre el pago real y el estipulado acababa en el bolsillo de dichos funcionarios. ${ }^{54}$ Por su parte, la SEP dejaba habitualmente descubiertas las plazas cuando se presentaba una baja y sólo fundó un puñado de escuelas en el periodo del fideicomiso. Tanto la Secretaría de Educación como el Gobierno federal hicieron patente que su celo en vigilar el respeto de la Ley Federal del Trabajo crecía cuando las responsabilidades recaían mayoritariamente sobre propietarios extranjeros. Mientras tanto, los trabajadores continuaron exigiendo su derecho a la educación, aún cuando estaba claro que los días del populismo educativo eran sólo lejanos recuerdos.

51 Ibidem, pp. 182-186.

52 Montiel, 1979, p. 225; "Confisca el gobierno federal las negociaciones alemanas y japonesas afectadas de acuerdo con la nueva ley”, El Sur de México, Tapachula, 18 de junio de 1942, XVII928, p. 1. Véase también Von Mentz, 1988, pp. 199-202.

53 Benjamin, 1995, p. 234.

54 En torno a la contratación de guatemaltecos por parte del Fideicomiso, véase AGN, Ramo Presidentes, Avila Camacho, 546.2/10. Jesús Jiménez y Romeo Noriega, Federación de Trabajadores de Chiapas, y el diputado Fidel Martínez, presidente de la Comisión Permanente, al presidente de la República, desde Tuxtla Gutiérrez, Chis., 7 de septiembre de 1944. 


\section{Conclusión}

No debe sorprender el fracaso de las escuelas Artículo 123 en Chiapas, dada la relativa debilidad de la SEP en el momento de su federalización, la dinámica del poder en la zona de mayor exportación de Chiapas y la lucha de clases en el Soconusco durante los años treinta. En consecuencia de las maniobras de los hacendados, así como de la impotencia de la SEP, la mayoría de los maestros de las escuelas Artículo 123 se enfrentaron a grandes adversidades. En 1935, cuando existía un mayor número de este tipo de planteles, Septimio Pérez Palacios lo señaló en un informe a los altos mandatarios de la SEP en el Distrito Federal:

Durante enero no funcionaron buen número de estas [escuelas Artículo 123]. La razón es muy sencilla, cada candidato en la mayoría de las ocasiones tiene que aguantar hasta 4 y 6 meses sin sueldo, mientras les imponemos multas a los finqueros y les seguimos la acción correspondiente. Las multas y todo lo que viene, no garantizan un solo centavo para el maestro, porque nuestros legisladores no pensaron en este inconveniente. Así es que para encontrar gentes heroicas que se enfrenten con situaciones de hambre, en que pueden ser hasta asesinados, en lugares terribles por el clima e incomunicación, ya tenemos necesidad de no pocos esfuerzos. ${ }^{55}$

En un artículo importante, Alan Knight señaló que las políticas radicales y populares de la Revolución Mexicana fueron frustradas por las "armas de los poderosos". Según Knight, éstos se previnieron de que el proyecto cardenista en su conjunto tuviera éxito: de hecho, garantizaron el fracaso del mismo. La resistencia al proyecto cardenista asumía dos formas: por una parte, los sinarquistas, ciertos caciques, y un grupo de líderes de empresas intentaron afrontarlo directamente; por la otra, una agrupación más grande y más exitosa se dio cuenta de que sólo conspirar inteligentemente podría minar y lograr el fracaso del proyecto oficial. ${ }^{56}$ Debemos colocar a los finqueros chiapanecos de origen alemán en este segundo grupo. Tras el uso de las "armas de los poderosos", la elite chiapaneca golpeó sistemáticamente el proyecto hasta que la SEP adoptó una orientación conservadora más a su gusto.

Irónicamente, mientras los propietarios adinerados disfrutaban de un éxito palpable en hacer decaer las escuelas Artículo 123, el Estado mexi-

55 AHSEP, DER, Delegación Chiapas, 236, 10, f. 16. El director federal de Educación Septimio Pérez Palacios a la SEP, DER, desde Tuxtla Gutiérrez, Chis., 5 de febrero de 1935.

56 Knight, 1994, p. 100. 
cano ganaba fuerza en otros frentes en Chiapas durante la época cardenista. En otras palabras, la clase finquera y ranchera ganó la batalla contra la SEP, pero (momentáneamente) perdió la guerra contra el Gobierno federal. Aunque la mayoría de las escuelas Artículo 123 ya habían sido clausuradas para 1942, hasta entonces los maestros pudieron impulsar la reforma agraria, incorporar a los trabajadores y campesinos a los Sindicatos oficiales y ejecutar varias funciones como inspectores laborales, oficiales de inmigración y agentes de un emergente Estado-nación. En parte gracias a las labores de los maestros Artículo 123, en 1939 las condiciones en Chiapas eran finalmente propicias para la reforma agraria y el gobernador dio el paso simbólico de expropiar las tierras del antes intocable finquero de origen alemán Enrique Braun. Después del embargo de la mayoría de las plantaciones cafetaleras alemanas en 1942, el gobierno federal y la SEP renunciaron a la oportunidad que se les presentaba de profundizar la reforma agraria y, al mismo tiempo, de revivir el programa de las escuelas Artículo 123. Además de que ambas iniciativas contradecían las tendencias ideológicas del gobierno de Manuel Avila Camacho (1940-1946), el hecho de que el gobierno federal ya no necesitara escuelas populistas, movilizantes y —al fin y al cabo- corporativistas, explica probablemente el abandono del proyecto educativo Artículo 123.

Recibido el 23 de junio de 2010 Aceptado el 19 de septiembre de 2010

\section{Bibliografía}

Friederike Baumann: "Terratenientes, campesinos y la expansión de la agricultura capitalista en Chiapas, 1896-1916”, Mesoamérica, 5, Woodstock, 1983, pp. 8-63.

Thomas Benjamin: Chiapas: tierra rica, gente pobre. Historia política y social, México, Grijalbo, 1995.

Antonio García de León: Resistencia y utopía: memorial de agravios y crónica de revueltas y profecías acaecidas en la provincia de Chiapas durante los últimos quinientos años de su historia, México, Ediciones Era, 1985, Tomo 2.

Harvey Graff: The Literacy Myth: Literacy and Social Structure in the NineteenthCentury City, San Francisco, Academic Press, 1979.

Friedrich Katz: The Secret War in Mexico, Chicago, University of Chicago Press, 1981. 
Alan Knight: “Cardenismo: Juggernaut or Jalopy?”, Journal of Latin American Studies, 26-1, London, 1994, pp. 73-107.

Stephen E. Lewis: The Ambivalent Revolution: Forging State and Nation in Chiapas, 1910-1945, Albuquerque, University of New Mexico Press, 2005.

Engracia Loyo: “Escuelas Rurales 'Artículo 123' (1917-1940)”, Historia Mexicana, XL-2, México, 1991, pp. 299-336.

Murdo MacLeod: Spanish Central America. A Socioeconomic History, 1520-1720, Berkeley, University of California Press, 1973.

Brígida von Metz, "Las empresas alemanas en México (1920-1942)", en Ricardo Pérez Montfort, Verena Radkau y Daniela Spencer (eds.): Los empresarios alemanes, el Tercer Reich, y la oposición de derecha a Cárdenas, México, CIESAS, 1988, Tomo 1, pp. 214-216.

David McCreery: Rural Guatemala 1760-1940, Stanford, Stanford University Press, 1994.

Gustavo Montiel: Recordando el Soconusco y su perla, México, B. Costa-Amic, 1979.

María de los Angeles Ortíz y Bertha Toraya: Concentración de poder y tenencia de la tierra. El caso de Soconusco, México, CIESAS, Cuadernos de la Casa Chata 125, 1985.

Septimio Pérez Palacios: "Mi labor en el sector educativo", en Los Maestros y la Cultura Nacional, 1920-1952, Vol. 5. Sureste, México, Museo Nacional de Culturas Populares y Dirección General de Culturas Populares, 1987, pp. 73-92.

Susana Quintanilla y Mary Kay Vaughan (coords.): Escuela y sociedad en el período cardenista, México, Fondo de Cultura Económica, 1997.

Elsie Rockwell: "Schools of the Revolution: Enacting and Contesting State Forms in Tlaxcala, 1910-1930", en Gilbert M. Joseph y Daniel Nugent (coords.): Everyday Forms of State Formation: Revolution and the Negotiation of Rule in Modern Mexico, Durham, Duke University Press, 1994, pp. 170-208.

Friedrich E. Schuler: Mexico between Hitler and Roosevelt. Mexican Foreign Relations in the Age of Lázaro Cárdenas, 1934-1940, Albuquerque, University of New Mexico Press, 1998.

Secretaría de Educación Pública (SEP): Memoria relativa al estado que guarda el ramo de educación pública el 31 de agosto de 1934, México, Talleres Gráficos de la Nación, 1934, Tomo II, Documentos.

Daniela Spenser: "The Formation of a Coffee Economy in Chiapas", en Thomas Benjamin y William McNellie (coords.): Other Mexicos: Essays on Regional Mexican History, 1876-1911, Albuquerque, University of New Mexico Press, 1984, pp. 123-143.

_ "Los inicios del cultivo del café en Soconusco y la emigración extranjera", en Brígida von Mentz, Ricardo Pérez Monfort, Verena Radkau y Daniela 
Spenser: Los empresarios alemanes, el Tercer Reich y la oposición de derecha a Cárdenas, México, CIESAS, Ediciones de la Casa Chata, 1988, pp. 65-78, Tomo I.

Mary Kay Vaughan: Cultural Politics in Revolution, Tucson, University of Arizona Press, 1997.

Juan Pedro Viqueira: "Éxitos y fracasos de la evangelización en Chiapas (15451850)", en Nelly Sigaut (ed.): La iglesia católica en México, Zamora, El Colegio de Michoacán, 1997, pp. 69-98. 